\title{
Preoperative Angioembolization for Spleen Preservation in Grade IV Spleen Injury with Combined Abdominal Trauma
}

\author{
Chan Yong Park', Seon Hee Kim¹, Hyun Min Cho', Hoon Kwon², Chang Ho Jeon², \\ Chang Won Kim \\ ${ }^{1}$ Department of Trauma Surgery, Pusan National University Hospital, Busan, Korea \\ ${ }^{2}$ Department of Radiology, Pusan National University Hospital, Busan, Korea
}

A 51-year-old man was admitted to the emergency department. A grade IV spleen injury with contrast extravasation was revealed by an abdominal CT scan. We elected to perform an emergency laparotomy because of severe edema within the small intestines and bleeding from the greater omentum. For a safe preservation of the spleen, a transcatheter arterial embolization was performed before the laparotomy. During the laparotomy, hemostatic agents such as thrombin and the gelatin gel $\left(\right.$ FloSeal $\left.^{\circledR}\right)$ and Surgicel ${ }^{\circledR}$ were applied for bleeding control around the spleen. The patient was discharged without complications on $6^{\text {th }}$ day postoperatively.

(Trauma Image Proced 2017(2):79-83)

Key Words: Grade IV spleen injury; Contrast extravasation; Spleen-preserving surgery; Transcatheter arterial embolization; Hemostatic agents

\section{CASE}

A 51-year-old man was admitted to the emergency department complaining of abdominal pain in the left upper quadrant after a traffic accident. The initial vital signs were stable: systolic blood pressure, $120 / 60 \mathrm{mmHg}$; pulse rate, 98 beats/min; respiration rate, 18 breaths $/ \mathrm{min}$; body temperature, $36.4{ }^{\circ} \mathrm{C}$; oxygen saturation, $97 \%$ respectively. Laboratory examination revealed a WBC $23.3 \times 10^{3} / \mathrm{uL}, \mathrm{Hb} 12.7 \mathrm{~g} / \mathrm{dL}$, platelet $211 \times 10^{3} / \mathrm{uL}$, lactic acid $2.9 \mathrm{mmol} / \mathrm{L}$, base excess -2.1. Abdominal CT revealed a grade IV spleen injury with a contrast extravasation, partial infarction in the left kidney, and a left adrenal hematoma (Fig. 1). We decided to undergo an emergency laparotomy because of severe edema of the small intestine and bleeding from the greater omentum (Fig. 2). We elected to perform a transcatheter arterial embolization (TAE) before the laparotomy to safely preserve the spleen. The spleen and left kidney were embolized at 66 minutes after admission. Histoacryl was used for the control of active bleeding from the spleen and gelfoam was used to reduce the blood flow in the injured area (Fig. 3). Then, a laparotomy was performed. Hemostatic agents such as thrombin and the gelatin gel $\left(\right.$ FloSeal $\left.^{\circledR}\right)$ and Surgicel ${ }^{\circledR}$ were applied for bleeding control around the spleen (Fig. 4). A follow-up abdominal CT was performed on the $4^{\text {th }}$ day after the surgery, and approximately one-quarter of the spleen

Received: November 2, 2017 Revised: November 8, 2017 Accepted: November 8, 2017

Correspondence to: Chan Yong Park, Department of Trauma Surgery, Pusan National University Hospital, Busan, Korea, 179, Gudeok-Ro, Seo-Gu, Busan, 49241, Korea

Tel: 82-51-240-7369, Fax: 82-51-240-7719, E-mail: wkafyddl@hanmail.net

Copyright (c) 2017 Korean Association for Research, Procedures and Education on Trauma. All rights reserved.

@This is an open-access article distributed under the terms of the Creative Commons Attribution Non-Commercial License (http://creativecommons.org/ licenses/by-nc/4.0) which permits unrestricted noncommercial use, distribution, and reproduction in any medium, provided the original work is properly cited 


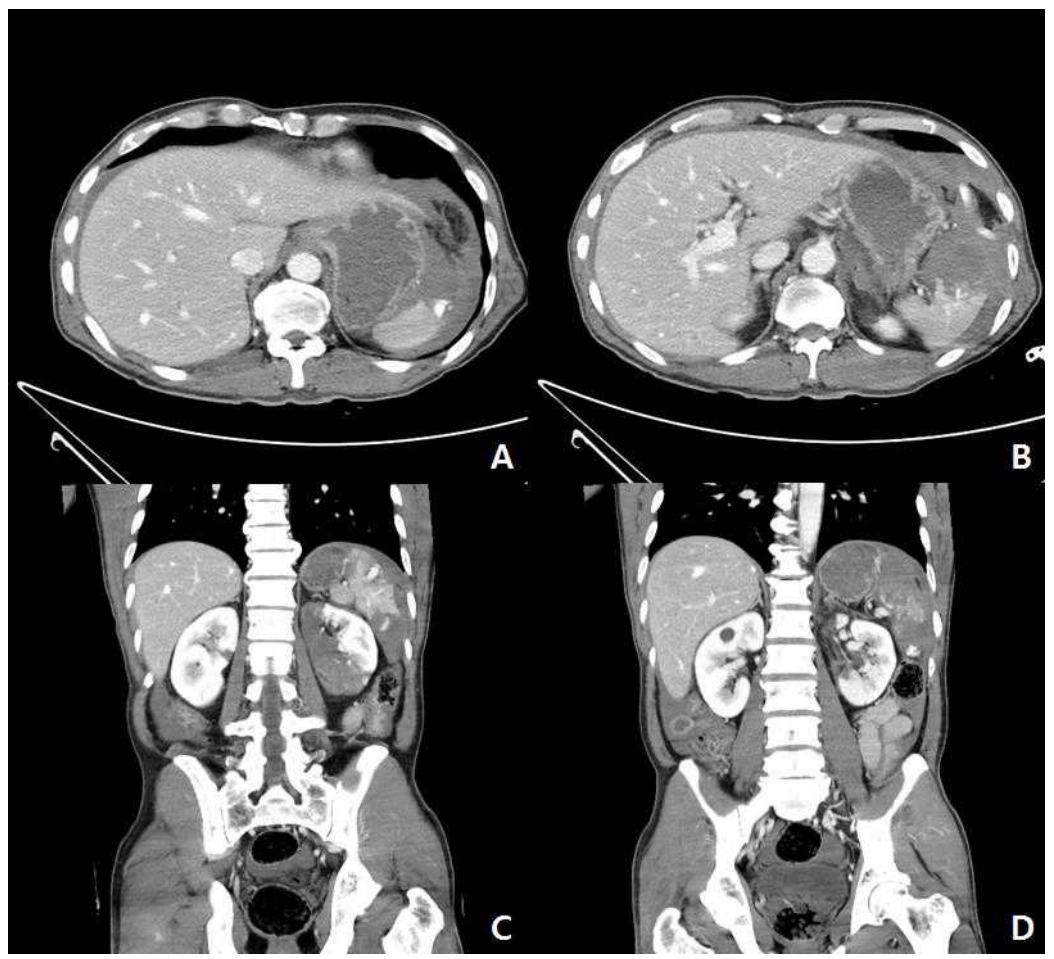

Fig. 1. Abdominal CT shows a contrast extravasation from mid portion $(A, C)$ and inferior pole $(\mathrm{B}, \mathrm{D})$ of the spleen in axial and the coronal view.

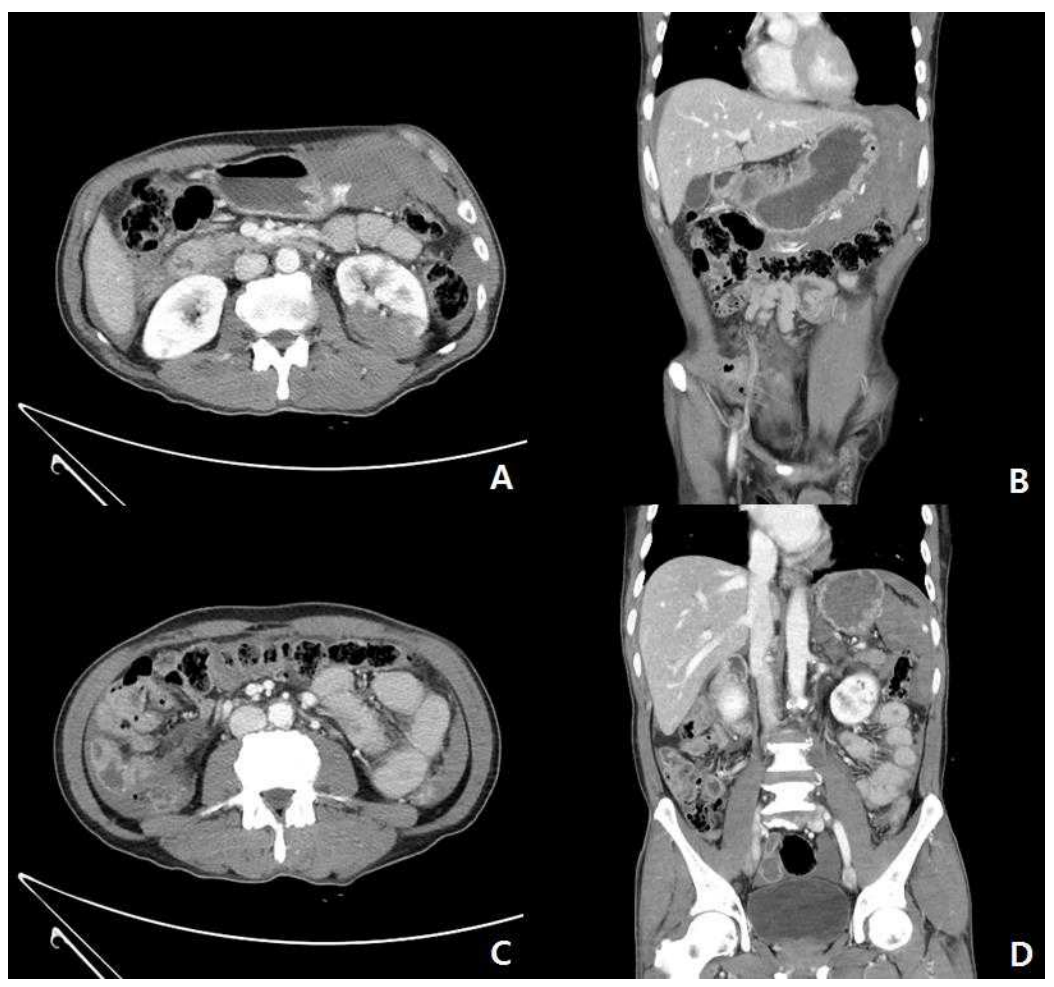

Fig. 2. Abdominal $C T$ shows contrast extravasation near the greater curvature of the stomach (A, B) and severe swelling of the small intestine on the left side. (C, D) 


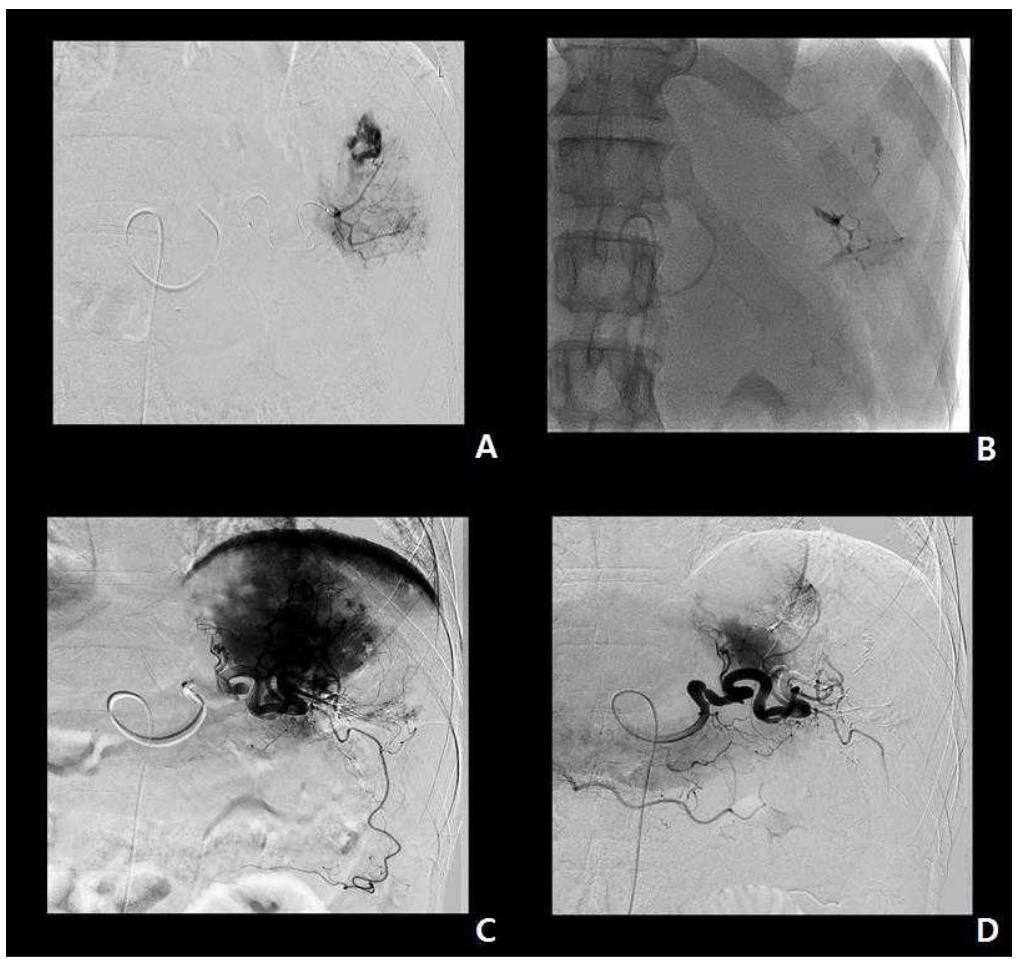

Fig. 3. Transcatheter arterial angiography shows active bleeding from the spleen (A). Therefore, embolization was performed using histocryl (B). A splenic angiography was performed again, and an overall oozing pattern was observed(C). Gelfoam was used to reduce the blood flow in the injured area of the spleen. Then a little spleen parenchyma was imaged (D).

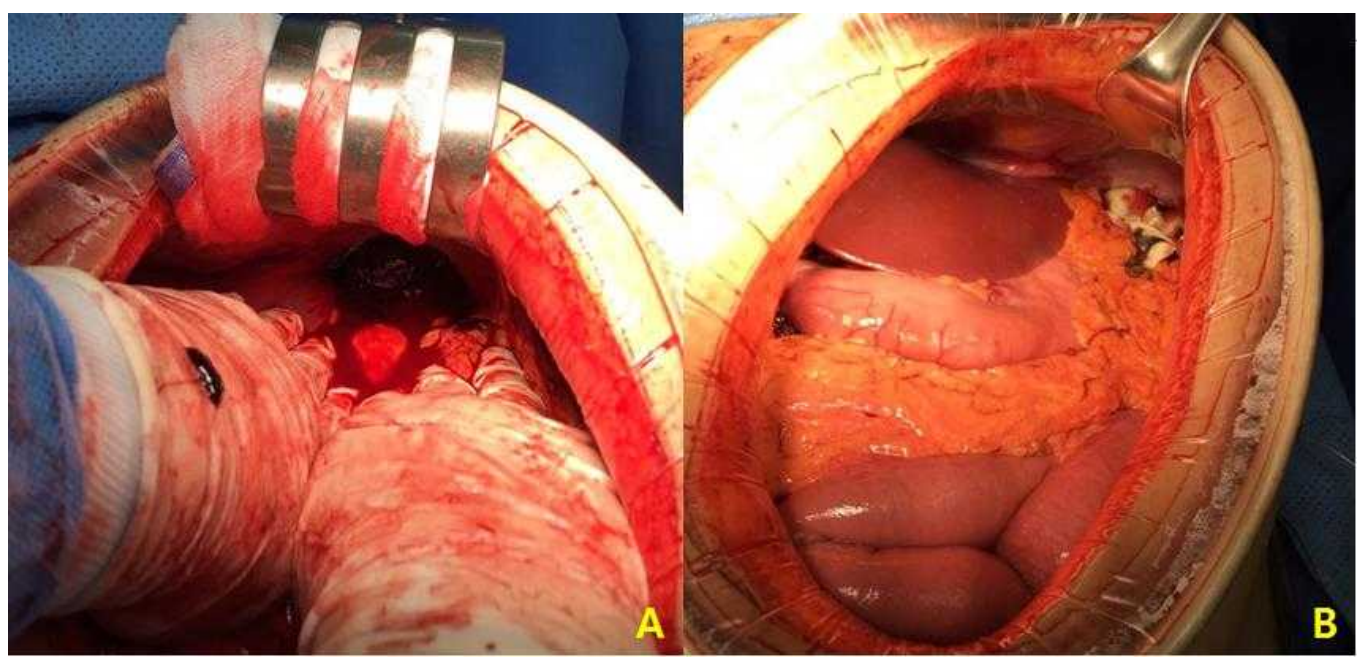

Fig. 4. A hematoma is seen in the perisplenic space on laparotomy $(A)$. After removal of the hematoma, hemostatic agents (Surgicel and Floseal) were applied (B). 


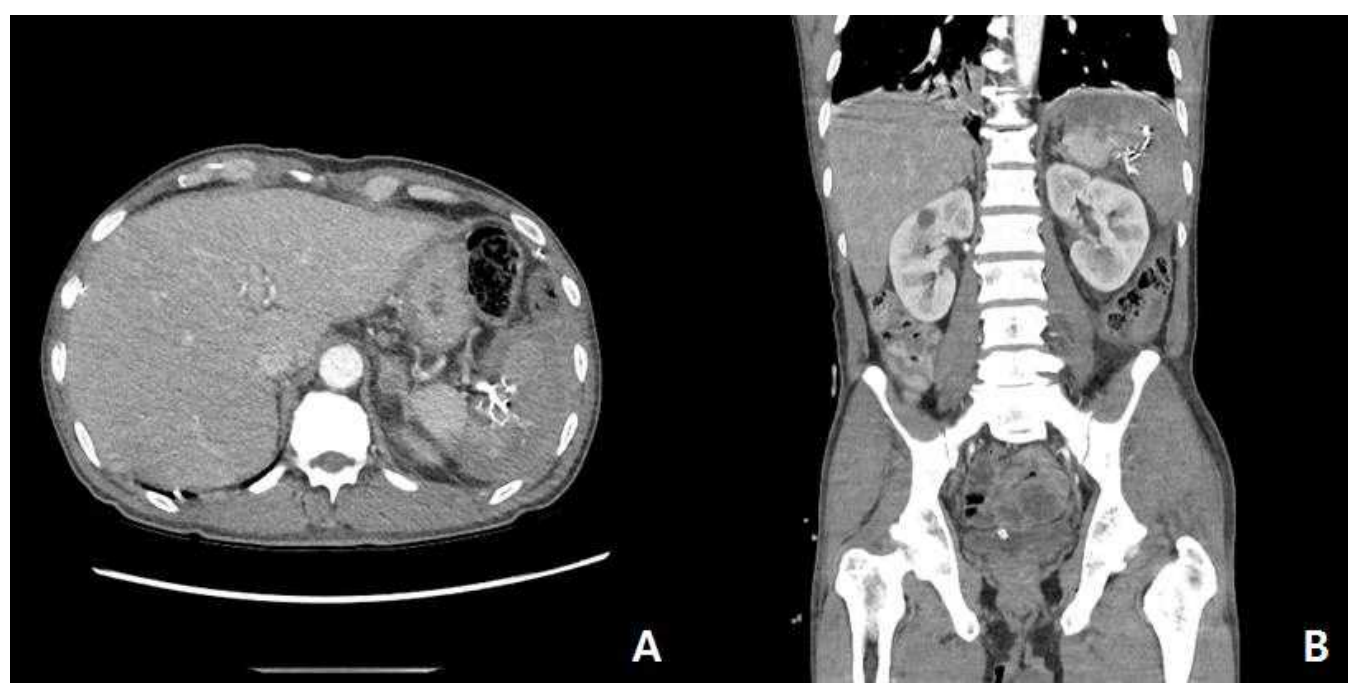

Fig. 5. A follow-up abdominal CT was performed on the 4th day after surgery, and about $20 \%$ of the spleen was preserved with no evidence of bleeding.

was preserved with no evidence of bleeding (Fig. 5). Laboratory examination revealed WBC $12.7 \times 10^{3} / \mathrm{uL}$, $\mathrm{Hb} 11.4 \mathrm{~g} / \mathrm{dL}$, platelet $309 \times 10^{3} / \mathrm{uL}$. The patient was discharged without complications on $6^{\text {th }}$ day postoperatively.

\section{DISCUSSION}

Grade IV spleen injury caused by blunt abdominal trauma is usually treated with a TAE or splenectomy. Splenectomy is frequently performed if laparotomy is necessary due to other combined abdominal injuries.

However, Kristinsson et al. (1) reported the importance of the spleen in a study of 8,149 cancer-free veterans who followed up for 27-years after splenectomy. They found that the risk of hospitalization for pneumonia, meningitis, septicemia, DVT, pulmonary embolism, and cancer increased in patients who underwent splenectomy. Skattum et al. (2) also emphasized the immune function of the spleen and the risk of overwhelming postsplenectomy infection. Demetriades et al. (3) reported that splenectomy is an independent risk factor for early infectious complications. Therefore, it is very important to preserve the spleen in splenic injuries. Even if surgery is unavoidable, spleen-preserving surgery should be considered. Spleen-preserving or spleen-tissue-conserving surgery is a favorable surgical procedure for spleen injury (4). Spleen-preserving surgery reduces mortality, postoperative complications, and length of hospital stay (5). Therefore, we attempted to preserve the spleen in a patient with grade IV spleen injury with active bleeding which required an emergency laparotomy due to other combined abdominal injuries. So we performed a laparotomy after TAE to preserve the spleen without manipulation of the spleen during surgery.

Selective embolization of splenic injuries can lead to complications such as continuous bleeding, splenic infarcts, and splenic abscesses. Proximal embolization of the splenic artery (PSAE) reduces splenic blood pressure with ischemia with the help of a collateral blood supply (6). In this case, histoacryl was used for hemostasis of the active bleeding locations in the spleen, and gelfoam was used to reduce the blood flow in the injured area of the spleen. This method was performed to prevent bleeding from the collateral blood supply.

After resolution of other combined abdominal injuries during operation, hemostasis was performed using hemostatic agents $\left(\right.$ FloSeal $^{\circledR}$ and Surgicel $\left.{ }^{\circledR}\right)$ around the spleen. Thanks to TAE, there was no active bleeding from the spleen during the operation.

Several methods have been attempted to preserve the spleen in patients requiring laparotomy. Ligation in the 
proximal and middle part of the splenic artery for spleen-preservation $(5,7)$ and partial resection of the spleen is performed $(8,9)$. There is also a recent report on spleen auto transplantation (10).

We believe that the use of TAE before surgery in patients with spleen injury with active bleeding requiring laparotomy may be helpful in spleen-preservation and could shorten the time of operation.

\section{Conflict of Interest Statement}

None of authors has a conflict of interest.

\section{REFERENCES}

1. Kristinsson SY, Gridley G, Hoover RN, Check D, Landgren O. Long-term after splenectomy among 8,149 cancer-free American veterans: a cohort study with u to 27 years follow-up. Haematologica 2014:99:392-8.

2. Skattum J, Naess PA, Gaarder C. Non-operative management and immune function after splenic injury. Br J Surg 2012;99:59-65.

3. Demetriades D, Scalea TM, Degiannis E, Barmparas G, Konstantinidis A, Massahis J, et al. Blunt splenic trauma: splenectomy increases early infectious complications: a prospective multicenter study. J Trauma Acute Care Surg
2012;72:229-34.

4. Meyer L, Uberruck T, Koch A, Gastinger I. Resection of the spleen using the Water Jet dissection technique. J Laparoendosc Adv Surg Tech A 2004;14:321-4.

5. Alimov AN, Isaev AF, Safronov EP, Otlygin IuV, Useinov EB, Muradov IU. Choice of the method of surgical treatment of spleen disruption in combined and isolated abdominal trauma in terme of endosurgery. Khirugiia (Mosk) 2006;(3):43-9.

6. Zmora O, Kori Y, Samuels D, Kessler A, Schulman CI, Klausner JM, et al. Proximal Splenic Artery Embolization In Blunt Splenic Trauma. Eur J Trauma Emerg Surg 2009;35:108.

7. Alimov AN, Zubarev AR, Priamikov AD, Alimov VA, Sukiasian AA, Murashina IV, et al. The organ-preserving surgical treatment of the splenic rupture after the blunt abdominal trauma. Khirurgiia (Mosk) 2013;(9):39-43.

8. Navas-Cuella JA, Canete-Gomez J, Lopez-Bernal F, GarciaRivera C, Pareja-Ciuro F, Padillo-Ruiz J. Spleen-preserving surgery after blunt abdominal trauma with splenic hilum involvement. Cir Cir 2015;83:516-21.

9. Eskandarlou M, Derakhshanfar A. Introduction of a simple technique for partial splenectomy in multiple trauma patients. Iran Red Crescent Med J 2013:15:e9072.

10. Di Carlo I, Pulvirenti E, Toro A. A new technique for spleen autotransplantation. Surg Innov 2012;19:156-61. 